\title{
Development of Three Methods for Simultaneous Quantitative Determination of Chlorpheniramine Maleate and Dexamethasone in the Presence of Parabens in Oral Liquids
}

\author{
Hany W Darwish ${ }^{1,2 *}$, Fadia H Metwally ${ }^{2,3}$ and Abdelaziz El Bayoumi ${ }^{2}$ \\ ${ }^{1}$ Department of Pharmaceutical Chemistry, College of Pharmacy, King Saud University, PO Box 2457, Riyadh 11451, Saudi \\ Arabia, ${ }^{2}$ Department of Analytical Chemistry, Faculty of Pharmacy, Cairo University, Kasr El-Aini Street, ET 11562, Cairo, \\ Egypt, ${ }^{3}$ Ibn Sina National College for Medical Studies, AIMahjer Road, Jeddah, Saudi Arabia
}

*For correspondence: Email: hdarwish75@yahoo.com, hdarwish@ksu.edu.sa; Tel: +966-14677343; Fax: +966-14676220

\begin{abstract}
Purpose: To develop new selective, precise, and accurate methods for the simultaneous determination of chlorpheniramine maleate (CHP) and dexamethasone (DX) in the presence of methyl and propyl paraben in phenadone syrup.

Methods: In the first two methods, the predictive abilities of principal component regression (PCR) and partial least squares (PLS), respectively, were examined for the analysis of the quaternary mixture. The third method, high performance thin layer chromatography (HPTLC)-densitometric method, was based on the separation of the mixture on silica gel plates using chloroform: methanol (93:7, v/v) as a mobile phase.

Results: All the proposed methods were successfully applied to the analysis of raw materials and dosage form. For PCR method, recovery of chlorpheniramine maleate and dexamethasone in the dosage form was $98.89 \pm 1.736$ and $102.36 \pm 1.86 \%$, respectively while for. PLS method, recovery of chlorpheniramine maleate and dexamethasone was $98.94 \pm 1.69$ and $102.33 \pm 1.84$, respectively. On the other hand, recovery of the two analytes by HPTLC method was $100.72 \pm 1.05$ and $102.29 \pm 3.98$, respectively. The results obtained by applying the proposed methods were statistically analyzed and compared with those obtained by a reported HPLC method.

Conclusion: The proposed methods are fast, accurate and specific, and can be applied for the quantitative determination of the two analytes without interference from added excipient, thus obviating the need for preliminary extraction of analytes from the pharmaceutical formulation. Thus, they are suitable for use in quality control (QC) laboratories and pharmaceutical industry
\end{abstract}

Keywords: Chlorpheniramine maleate, Dexamethasone, Principal component regression, Partial least squares, High performance thin layer chromatography, Excipients

Tropical Journal of Pharmaceutical Research is indexed by Science Citation Index (SciSearch), Scopus, International Pharmaceutical Abstract, Chemical Abstracts, Embase, Index Copernicus, EBSCO, African Index Medicus, JournalSeek, Journal Citation Reports/Science Edition, Directory of Open Access Journals (DOAJ), African Journal Online, Bioline International, Open-J-Gate and Pharmacy Abstracts

\section{INTRODUCTION}

Chlorpheniramine maleate (CHP, Fig.1) [(3RS')3-(4-chloophenyl)-N, N-dimethyl-3-(pyridin-2-yl) propan-1-amine hydrogen (Z)-butenedioate] is an antihistaminic drug [1]. Dexamethasone (DX,
Fig.1) [9-fluoro-11ß, 17, 21-trihydroxy-16amethylpregna-1, 4-diene-3, 20-dione] is a corticosteroid anti-inflammatory agent [1]. CHP and DX were determined simultaneously in dosage form by HPLC methods[2,3], spectrofluorimetric method [4] chemometric 
<smiles>CN(C)CCC(c1ccc(Cl)cc1)c1ccccn1</smiles>

Chlorpheniramine maleate (CHP)

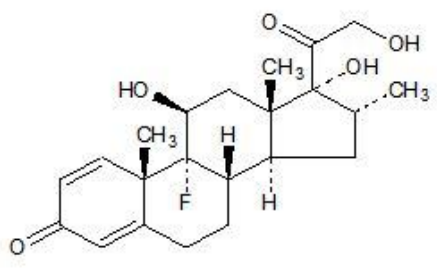

Dexamethasone (DX)

Figure 1: Chemical structures of Chlorpheniramine maleate and Dexamethasone

methods [5] and derivative spectrophotometric method [6]. Both drugs are formulated together in the local Egyptian market in the form of syrups for the relief of asthma [7] in addition to methyl paraben (MP) and propyl paraben (PP) as preservatives. To the best of our knowledge (upon extensive literature review), there is no reported method for the analysis of CHP and DX in presence of MP and PP. Therefore, the aim of this work was the application of multivariate calibration methods (PLS and PCR) and HPTLC methods for quantifying $\mathrm{CHP}$ and $\mathrm{DX}$ in their quaternary mixture with MP and $\mathrm{PP}$. The results obtained are reproducible. The advantages of the proposed methods are their speed, simplicity and no need for preliminary separation step.

\section{EXPERIMENTAL}

\section{Instruments}

1. A double beam UV-visible spectrophotometer (SHIMADZU, Japan) model UV-1601 PC with quartz cell of $1 \mathrm{~cm}$ pathlength, connected to IBM compatible computer. The software was UVPC personal spectroscopy software version 3.7. The spectral bandwidth was $2 \mathrm{~nm}$ and wavelength-scanning speed $2800 \mathrm{~nm} / \mathrm{min}$.

2. UV lamp with short wavelength $254 \mathrm{~nm}$ (USA).

3. TLC scanner 3 densitometer (Camag, Muttenz, Switzerland). The following requirements are taken into consideration:

- Slit dimensions: $5 \mathrm{~mm} \times 0.2 \mathrm{~mm}$.

- Scanning speed: $20 \mathrm{~mm} / \mathrm{S}$.

- Spraying rate: $10 \mu \mathrm{L} / \mathrm{s}$.

- Data resolution: $100 \mu \mathrm{m} / \mathrm{step}$.

4. TLC plates $(20 \mathrm{~cm} \times 10 \mathrm{~cm})$ coated with silica gel 60F254 (Merck, Germany).
5. Sample applicator for TLC Linomat IV with $100 \mu \mathrm{L}$ syringe (Camag, Muttenz, Switzerland).

\section{Software}

All multivariate calibration methods were implemented in Matlab® 7.1.0.246 (R14) using PLS toolbox software version 2.1. The t-test, Ftest and ANOVA were performed using Microsoft $\circledast$ Excel 2013. All calculations were performed using intel ®core TM i5-2400, 3.10 $\mathrm{GHz}, 4.00 \mathrm{~GB}$ of RAM under Microsoft Windows 7.

\section{Reagents and chemicals}

The reference compounds, chlorpheniramine maleate (CHP), dexamethasone (DX), methyl paraben (MP) and propyl paraben (PP), certified to contain 99.59, 99.73, 98.50 and $101.65 \%$, respectively, by the manufacturers, were kindly provided by The Arab Pharmaceuticals and Chemical Industries Company, Cairo, Egypt. Phenadone syrup was purchased from the Egyptian local market and had a labeled content of $0.4 \mathrm{mg} \mathrm{mL}^{-1} \mathrm{CHP}, 0.1 \mathrm{mg} \mathrm{mL}^{-1} \mathrm{DX}, 1 \mathrm{mg} \mathrm{mL}^{-1}$ $\mathrm{MP}$ and $0.2 \mathrm{mg} \mathrm{mL}^{-1} \mathrm{PP}$ (Batch no.630351). Methanol, chloroform and $0.1 \mathrm{~N} \mathrm{HCl}$ used were of spectroscopic grade.

\section{Standard stock and working solutions}

For PCR and PLS methods, stock standard solutions of CHP, DX, MP and PP were prepared separately by dissolving $100 \mathrm{mg}$ of CHP, $50 \mathrm{mg}$ DX, $50 \mathrm{mg} \mathrm{MP}$ and $100 \mathrm{mg} \mathrm{PP}$ in $100 \mathrm{~mL}$ methanolic $\mathrm{HCl}(1 \mathrm{~mL}$ methanol: $4 \mathrm{~mL}$ $0.1 \mathrm{~N} \mathrm{HCl}$ ). Corresponding working solutions were prepared by transferring accurately $25 \mathrm{~mL}$ from each stock standard solutions separately in $250 \mathrm{~mL}$ measuring flasks and volume was completed with methanolic $\mathrm{HCl}$. Solutions (xc) and $(x d)\left[0.125 \mathrm{mg} \mathrm{mL}^{-1}\right]$ were also prepared by methanolic $\mathrm{HCl}$. 
For HPTLC-densitometric method, stock standard solutions of CHP, DX, MP and PP were prepared separately by dissolving $100 \mathrm{mg}$ of CHP, $100 \mathrm{mg} \mathrm{DX}, 200 \mathrm{mg} \mathrm{MP}$ and $100 \mathrm{mg}$ PP in $100 \mathrm{~mL}$ methanol. Working solution of DX $(0.2$ $\mathrm{mg} \mathrm{mL}^{-1}$ ) was prepared by diluting $20 \mathrm{~mL}$ of its stock standard solutions into $100 \mathrm{~mL}$ measuring flasks with methanol.

\section{PCR and PLS methods}

\section{Calibration}

\section{Construction of a training set}

A training set composed of 17 mixtures was prepared by diluting different volumes of each of CHP, DX, MP and PP working solutions into a series of 25-mL measuring flasks, each flask was spiked with $250 \mu \mathrm{g}$ of CHP and $125 \mu \mathrm{g}$ of DX (from solutions $\mathrm{Xc}$ and $\mathrm{Xd}$ ), in addition to mixture no. 18 that contains spiked concentrations of CHP and DX, $10 \mu \mathrm{g} \mathrm{mL}^{-1}$ of MP and $2 \mu \mathrm{gL}^{-1}$ of PP. All flasks were diluted to volume with methanolic $\mathrm{HCl}$. The absorption spectra of all 18 mixtures were recorded between 200-300 nm. The data points of the spectra were collected at every $1 \mathrm{~nm}$.

\section{Pre-processing the data}

Reject the regions from 200- $215 \mathrm{~nm}$ and above $290 \mathrm{~nm}$. Mean centering of the data was performed.

3. Selection of the optimum numbers of latent variables

Root mean square error of cross validation (RMSECV) values were calculated using cross validation method, leaving out one sample at a time to select the optimum number of factors.

\section{Validation}

A validation set composed of 8 mixtures containing different concentrations of CHP, DX, MP and PP was prepared to check the performance of the developed models.

\section{Application to pharmaceutical preparation (Phenadone syrup)}

Five $\mathrm{mLs}$ of phenadone syrup equivalent to $2 \mathrm{mg}$ of CHP, $0.5 \mathrm{mg}$ of DX, $5 \mathrm{mg}$ of MP and $1 \mathrm{mg}$ of PP was diluted to $100 \mathrm{~mL}$ with methanolic $\mathrm{HCl}$, further dilution was made by taking $5 \mathrm{~mL}$ of the above solution in $25-\mathrm{mL}$ measuring flask, $250 \mu \mathrm{g}$ of CHP and $125 \mu \mathrm{g}$ of DX were spiked and volume was completed by methanolic $\mathrm{HCl}$. The general procedures described under calibration were followed and the concentration of each compound was calculated.

\section{HPTLC-densitometric method}

Different volumes (1.0, 2.0, 3.0, 4.0, 5.0, and 6.0 $\mu \mathrm{L})$ of CHP working solution (1.00 mg mL $\left.{ }^{-1}\right)$ and $(2.0,4.0,6.0,8.0,9.0$ and $10.0 \mu \mathrm{L})$ of $\mathrm{DX}$ working solution $\left(0.20 \mathrm{mg} \mathrm{mL}^{-1}\right)$ were spotted on two separate TLC plates using the Camag TLC sampler. Bands are spaced $1 \mathrm{~cm}$ apart from each other and from the bottom edge of the plate. TLC plates were developed at room temperature in a chromatographic tank previously saturated with the mobile phase chloroform: methanol $(93: 7 \mathrm{v} / \mathrm{v})$, by ascending chromatography to a distance $8 \mathrm{~cm}$ from the bands at room temperature. The plates were left to dry then the bands were visualized under UV lamp $(254 \mathrm{~nm})$. The bands were scanned at 254 $\mathrm{nm}$. The peak area was recorded and the calibration curve was constructed by plotting the integrated peak area versus the corresponding concentrations of CHP and DX and the regression equation was computed.

\section{Assay of laboratory-prepared mixtures}

In a series of $10-\mathrm{mL}$ measuring flasks, aliquots of $\mathrm{CHP}, \mathrm{DX}, \mathrm{MP}$ and $\mathrm{PP}$ were transferred accurately from their corresponding stock and working solutions to prepare different mixtures and then complete to volume with methanol. Ten $\mu \mathrm{l}$ of the laboratory prepared mixtures was applied to a silica gel plate and continue under the above described conditions. The integrated peak were recorded and the concentrations of $\mathrm{CHP}$ and DX were calculated either by substituting in the corresponding regression equations or by comparing to a standard spotted, developed and scanned under the above mentioned conditions.

\section{Application to commercial pharmaceutical preparation (phenadone syrup)}

Five $\mathrm{mLs}$ of phenadone syrup equivalent to $2 \mathrm{mg}$ of CHP, $0.5 \mathrm{mg}$ of DX, $5 \mathrm{mg}$ of MP and $1 \mathrm{mg}$ of PP was diluted to $25 \mathrm{~mL}$ with methanol. On a TLC plate, four $\mu \mathrm{L}$ of the prepared solution was spotted and scanned under the above mentioned conditions.

The concentrations of CHP and DX were calculated either from the regression equation or by comparing to a standard spotted, developed and scanned under the same conditions. 


\section{RESULTS}

Figure 2 shows the absorption spectra of CHP, $D X, M P$ and $P P$. The main problem in the analysis of this mixture is that $\mathrm{CHP}$ and $\mathrm{DX}$ possess only a low absorbance in the UV-region comparing to MP and PP, moreover, the problem is further complicated because CHP and DX are present as minor components in the combination and MP is a major one. Thus, this work was devoted to the simultaneous determination of CHP and DX in the presence of MP and PP, which are available together in the form of syrups. This was achieved using multivariate calibration (PCR and PLS) and HPTLCdensitometric methods.

\section{PCR and PLS}

The multivariate calibration requires a careful experimental design of the standard composition of calibration set for providing the best predictions. Multilevel multifactor design [8] was used for the construction of the calibration set. PLS and PCR models were constructed using training set of 17 samples containing different ratios of $\mathrm{CHP}, \mathrm{DX}, \mathrm{MP}$ and $\mathrm{PP}$ in addition to mixture no. 18 that contains spiked concentrations of CHP and DX, $10 \mu \mathrm{g} \mathrm{mL}^{-1}$ of MP and $2 \mu \mathrm{g} \mathrm{mL}^{-1}$ of PP. The concentrations of CHP and DX were obtained in training and validation set by subtracting their concentrations in mix no. 18 in training set from their total concentrations in other mixtures. Table 1 shows the composition of the training set. PLS and PCR procedures were run on the calibration data of absorption (zeroorder) UV spectra and concentrations in validation set were calculated at the optimum number of factors. Number of factors used for constructing the models was 3 as shown in Figure 3. As the difference between the minimum RMSECV and other RMSECV values become smaller, the probability that each additional factor is significant becomes smaller [9]. The predicted concentrations of the calibration samples were plotted against the known concentrations to determine whether the model accounted for the concentration variation in the calibration set. Plots were expected to fall on a straight line with a slope of 1 and zero intercept. In order to validate proposed PLS and PCR methods, a validation set composed of 8 synthetic mixtures of CHP, DX, MP and PP were analyzed with the proposed PLS and PCR methods. Percent recovery of the validated samples are shown in Table 2.

The validation of the developed PCR and PLS models was assessed using several diagnostic tools. These tools were grouped into two categories in model diagnostic tools that are used to determine the quality of the model and sample diagnostic tools which are used to study the relationship between the samples and to identify unusual samples.

The predicted concentrations of the validation samples were plotted against the true concentration values. This was used to determine whether the model accounted for the concentration variation in the validation set. All plots had a slope of nearly one and an intercept close to zero (Table 3). The RMSEP was another diagnostic tool for examining the errors in the predicted concentrations, it indicates both the precision and accuracy [10]. The results in Table 3 indicating the high predictive abilities of the two models.

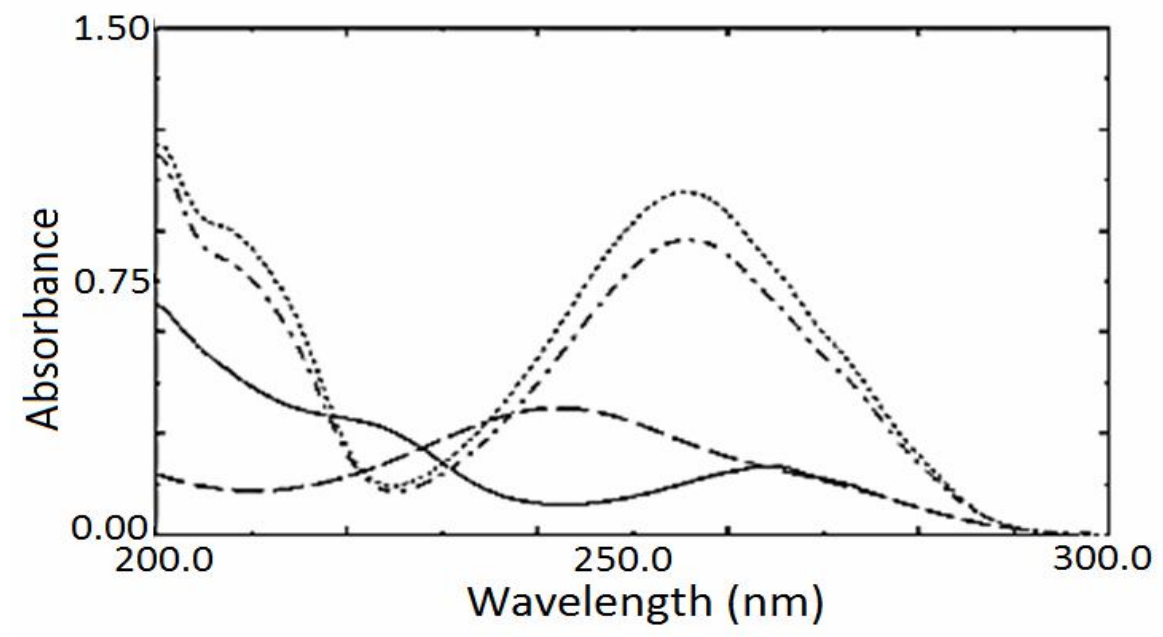

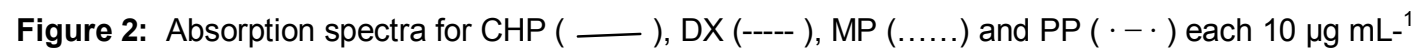


Table 1: The concentration of different mixtures of CHP, DX, MP and PP used in the training set

\begin{tabular}{|c|c|c|c|c|}
\hline Sample no. & $\mathrm{CHP}\left(\mu \mathrm{g} \mathrm{mL}^{-1}\right)$ & $\mathrm{DX}\left(\mu \mathrm{g} \mathrm{mL}^{-1}\right)$ & $M P\left(\mu g L^{-1}\right)$ & $P P\left(\mu g \mathrm{~mL}^{-1}\right)$ \\
\hline 1 & 22 & 6 & 2 & 0.4 \\
\hline 2 & 14 & 14 & 4 & 0.8 \\
\hline 3 & 30 & 8 & 10 & 2 \\
\hline 4 & 18 & 14 & 6 & 1.2 \\
\hline 5 & 30 & 10 & 2 & 0.4 \\
\hline 6 & 22 & 8 & 2 & 0.4 \\
\hline 7 & 18 & 8 & 8 & 1.6 \\
\hline 8 & 18 & 12 & 10 & 2 \\
\hline 9 & 26 & 14 & 8 & 1.6 \\
\hline 10 & 30 & 12 & 6 & 1.2 \\
\hline 11 & 26 & 10 & 10 & 2 \\
\hline 12 & 22 & 14 & 10 & 2 \\
\hline 13 & 30 & 14 & 2 & 0.4 \\
\hline 14 & 30 & 6 & 8 & 1.6 \\
\hline 15 & 14 & 12 & 2 & 0.4 \\
\hline 16 & 26 & 6 & 6 & 1.2 \\
\hline 17 & 14 & 10 & 8 & 1.6 \\
\hline 18 & 10 & 5 & 10 & 2 \\
\hline
\end{tabular}

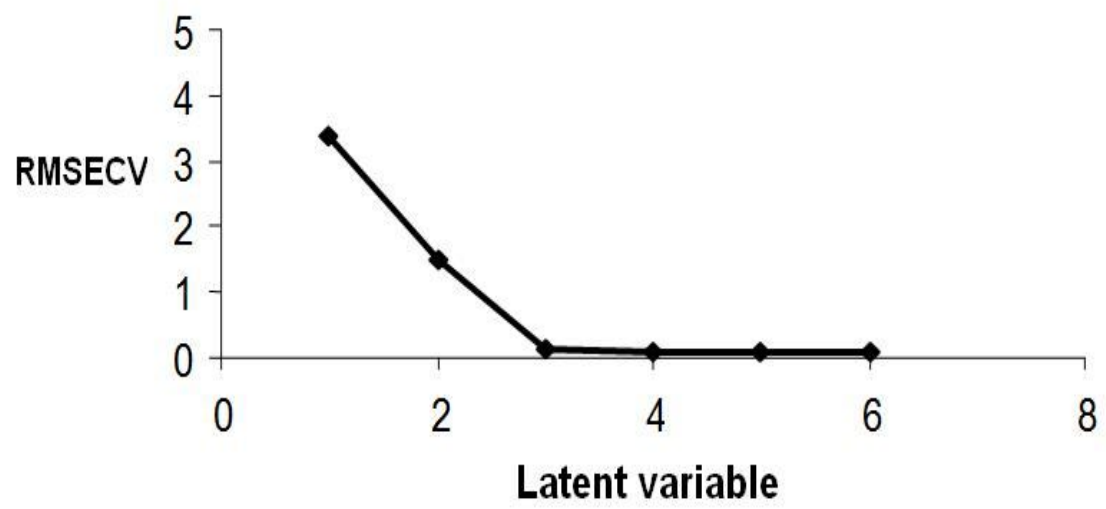

Figure 3: RMSECV plots for the cross validation results of the training set as a function of the number of factors used to construct the calibration models

Table 2: Determination of CHP and DX in validation set by the proposed multivariate calibration methods

\begin{tabular}{|c|c|c|c|c|c|c|c|c|}
\hline \multirow{3}{*}{$\begin{array}{l}\text { Mixture } \\
\text { no. }\end{array}$} & \multirow{2}{*}{\multicolumn{4}{|c|}{$\begin{array}{c}\text { Composition of mixture } \\
\left(\mu \mathrm{g} \cdot \mathrm{ml}^{-1}\right)\end{array}$}} & \multicolumn{4}{|c|}{ Recovery \% } \\
\hline & & & & & \multicolumn{2}{|c|}{ PLS method } & \multicolumn{2}{|c|}{ PCR method } \\
\hline & $\mathrm{CHP}$ & $D X$ & MP & $P P$ & CHP & $D X$ & CHP & $D X$ \\
\hline 1 & 14 & 8 & 6 & 1.2 & 100.57 & 99.81 & 99.25 & 99.08 \\
\hline 2 & 22 & 12 & 8 & 1.6 & 102.42 & 99.10 & 102.42 & 99.09 \\
\hline 3 & 26 & 12 & 4 & 0.8 & 99.77 & 100.49 & 99.77 & 100.48 \\
\hline 4 & 26 & 8 & 2 & 0.4 & 99.58 & 98.93 & 99.58 & 98.94 \\
\hline 5 & 18 & 6 & 4 & 0.8 & 99.03 & 99.49 & 99.03 & 99.48 \\
\hline 6 & 18 & 10 & 2 & 0.2 & 99.28 & 101.69 & 97.83 & 101.68 \\
\hline 7 & 14 & 6 & 10 & 2 & 101.34 & 98.41 & 102.00 & 98.40 \\
\hline 8 & 22 & 10 & 6 & 1.2 & 100.26 & 99.24 & 100.26 & 98.32 \\
\hline Mean & & & & & 100.28 & 99.65 & 100.02 & 98.70 \\
\hline RSD* (\%) & & & & & 1.137 & 1.035 & 1.527 & 0.321 \\
\hline
\end{tabular}

${ }^{*}$ Relative standard deviation

\section{HPTLC- densitometric results}

The proposed HPTLC method is applied as a simple and sensitive method for the determination of CHP and DX in presence of MP and PP as preservatives. The proposed technique is based on the difference of $\mathrm{RF}$ values of $\mathrm{CHP}(\mathrm{RF}=0.12 \pm 0.04), \mathrm{DX}(\mathrm{RF}=0.37$ $\pm 0.05)$ and Parabens (MP and PP) (RF $=0.67 \pm$ 0.03 ) as shown in Fig.4. 
Table 3: Summary of results obtained by applying the diagnostic tools for model validation of the multivariate calibration methods

\begin{tabular}{|c|c|c|c|c|}
\hline \multirow{2}{*}{ Validation parameter } & \multicolumn{2}{|c|}{ PCR } & \multicolumn{2}{|c|}{ PLS } \\
\hline & CHP & $D X$ & CHP & $D X$ \\
\hline \multicolumn{5}{|l|}{$\begin{array}{l}\text { a) Predicted vs. known } \\
\text { concentration plot }\end{array}$} \\
\hline 1- Slope & 0.9984 & 0.9976 & 0.9984 & 0.9976 \\
\hline 2- Intercept & 0.0371 & 0.0255 & 0.0366 & 0.0256 \\
\hline 3- Correlation coefficient & 0.9992 & 0.9984 & 0.9992 & 0.9988 \\
\hline $\begin{array}{l}\text { b) Residual vs. actual } \\
\text { concentration plot ( } \pm \text { error in } \\
\text { prediction) }\end{array}$ & 0.2865 & 0.1071 & 0.2308 & 0.0948 \\
\hline c) RMSEP * & 0.2579 & 0.1059 & 0.1924 & 0.0998 \\
\hline
\end{tabular}

${ }^{*}$ Root mean square error of prediction

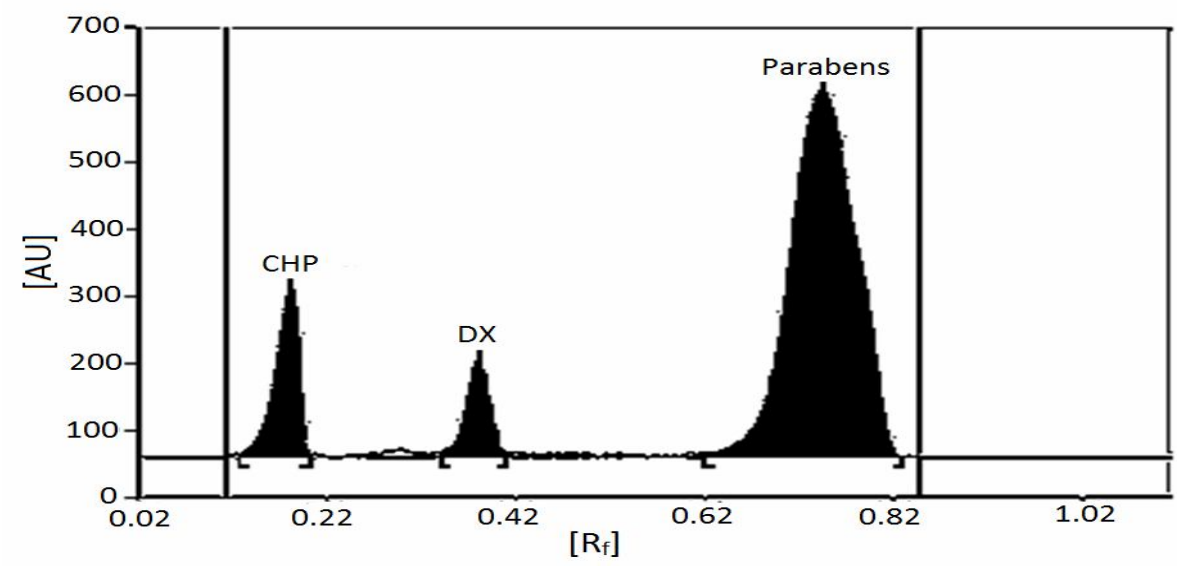

Figure 4: Thin layer chromatogram of CHP, DX and Parabens (MP and PP) using developing system, chloroform: methanol $(93: 7 \mathrm{v} / \mathrm{v})$

Different solvent systems were tried, and complete separation of the mixture was achieved using chloroform: methanol $(93: 7 \mathrm{v} / \mathrm{v})$ as a mobile phase. This separation allows the determination of $\mathrm{CHP}$ and $\mathrm{DX}$ without any interference from Parabens. CHP and DX bands were scanned at $254 \mathrm{~nm}$. To ensure good separation of bands, Parameters including resolution (Rs), peak symmetry, capacity factor (K'and selectivity factor $(\alpha)$ were calculated using parabens band. The resolution is always above 1.5 and an accepted value for symmetry and capacity factors was obtained, as shown in Table 4.

Table 4: Parameters of system suitability of the HPTLC method used

\begin{tabular}{lccc}
\hline Parameter & CHP & DX & Paraben \\
\hline Symmetry factor & 0.91 & 1.05 & 0.98 \\
Resolution $\left(\mathrm{R}_{\mathrm{s}}\right)^{\mathrm{a}}$ & 1.68 & 2.96 & \\
Capacity factor (K') & 0.82 & 0.45 & \\
\hline${ }^{\text {a Parameters were }}$ & calculated & using & parabens as \\
reference & & &
\end{tabular}

The proposed HPTLC-densitometric method was applied for the determination of CHP and DX in laboratory prepared mixtures containing different ratios of $\mathrm{CHP}, \mathrm{DX}$ and Parabens with mean accuracy of $101.46 \pm 1.813$ and $99.90 \pm 3.271$ for CHP and DX respectively. The results obtained are shown in Table 5. Assay validation sheet for HPTLC method was presented in Table 6. Oneway ANOVA was applied for the purpose of comparison of developed chemometric and HPTLC methods. Table 7 shows that there was no significant difference between them for the determination of CHP and DX in presence of MP and PP.

\section{Application to pharmaceutical preparation}

The proposed methods were successfully applied for the determination of CHP and DX in phenadone syrup. The results are shown in Table 8. Each value indicated is the mean of 4 determination of the same commercial batch. The validity of the proposed methods was further assessed by applying the standard addition 
technique. Results obtained are shown in Table 8. The results obtained for the analysis of CHP and DX in the pure powder form by the proposed method were statistically compared with those obtained by applying one of previously reported methods that used HPLC analysis (C18 column and $0.005 \mathrm{M}$ heptane sulphonic acid sodium salt in bi-distilled water: acetonitrile (70:30 v/v), $\mathrm{pH} 5)$ [2] but no significant difference was found between the results in terms of accuracy and precision (see Table 9).

Table 5: Determination of CHP and DX in laboratory prepared mixtures containing different percentages of MP and PP by the proposed HPTLC method

\begin{tabular}{|c|c|c|c|c|c|}
\hline \multicolumn{4}{|c|}{ Concentration ( $\mu \mathrm{g}^{\text {band }^{-1}}{ }^{-1}$} & \multicolumn{2}{|c|}{ Recovery \% } \\
\hline CHP & $D X$ & $M P$ & $P P$ & CHP & $D X$ \\
\hline 1 & 2 & 2 & 1 & 102.86 & 104.71 \\
\hline 2 & 2 & 4 & 2 & 101.37 & 101.88 \\
\hline 4 & 2 & 8 & 4 & 101.97 & 97.30 \\
\hline 4 & 1 & 10 & 2 & 98.40 & 97.54 \\
\hline 5 & 1 & 4 & 2 & 102.71 & 98.06 \\
\hline \multirow{2}{*}{\multicolumn{4}{|c|}{$\begin{array}{c}\text { Mean } \\
\text { SD* }^{*}\end{array}$}} & 101.46 & 99.90 \\
\hline & & & & 1.813 & 3.271 \\
\hline
\end{tabular}

*Standard deviation

Table 6: Assay parameters and method validation obtained by applying the proposed HPTLC method for CHP and DX

\begin{tabular}{|c|c|c|}
\hline \multirow[t]{2}{*}{ Parameter } & \multicolumn{2}{|c|}{ HPTLC method } \\
\hline & CHP & $D X$ \\
\hline Range $\left(\mu\right.$ band $\left.^{-1}\right)$ & $1-6$ & $0.4-2$ \\
\hline Slope & 1.7922 & 3.3431 \\
\hline Intercept & 1.4857 & 1.6395 \\
\hline Mean & 99.73 & 100.11 \\
\hline S.D. & 2.096 & 1.914 \\
\hline Variance & 4.393 & 3.663 \\
\hline Coff. of variation & 0.021 & 0.019 \\
\hline Correl. Coef.(r) & 0.9997 & 0.9996 \\
\hline${ }^{*} \operatorname{LOD}\left(\mu \mathrm{g}\right.$ band $\left.{ }^{-1}\right)$ & 0.173 & 0.169 \\
\hline${ }^{*} \mathrm{LOQ}\left(\mu \mathrm{g} \mathrm{band}^{-1}\right)^{\prime}$ & 0.524 & 0.512 \\
\hline${ }^{* *} \mathrm{RSD} \%^{\mathrm{a}}$ & $99.96 \pm 1.857$ & $100.72 \pm 1.520$ \\
\hline${ }^{* *} \mathrm{RSD} \%{ }^{\mathrm{b}}$ & $100.08 \pm 2.882$ & $98.88 \pm 2.913$ \\
\hline
\end{tabular}

"Limit of detection (LOD) and limit of quantification (LOQ) were determined by calculation; ${ }^{* *} R S D \%{ }^{a}$ and $R S D \%{ }^{b}$ are the intra-day and inter-day relative standard deviation, respectively $(n=4)$

Table 7: One-way ANOVA parameters for the different proposed methods used for the determination of CHP and DX

\begin{tabular}{llllll}
\hline Analyte & $\begin{array}{l}\text { Source of } \\
\text { variation }\end{array}$ & DF & $\begin{array}{l}\text { Sum of } \\
\text { squares }\end{array}$ & $\begin{array}{l}\text { Mean } \\
\text { square }\end{array}$ & F-value \\
\hline CHP & Between exp. & 2 & 6.842 & 3.421 & 1.594 \\
& Within exp. & 18 & 38.617 & 2.145 & \\
\hline DX & Between exp. & 2 & 0.668 & 0.334 & 0.102 \\
& Within exp. & 18 & 59.155 & 3.286 & \\
\hline
\end{tabular}

There was no significance difference between the methods using one-way ANOVA (F-test), where $F$ tabulated $=$ 3.555 at $p<0.05$

\section{DISCUSSION}

Both PLS and PCR techniques are listed under the multivariate calibration methods. They were successfully applied for the simultaneous determination of multi-components thus solving the problem of overlapping spectra of the relatively small absorptivity substances. PLS and
PCR techniques are spectral analyzing methods where the data are fit to many data points. PLS and PCR procedures are designated to be full spectrum computational procedures; however, using highly noisy, scarcely informative wavelengths detracts from precision. This can be lessened by discarding particularly noisy wave- 
Table 8A: Applying standard addition technique for determination of CHP and DX in phenadone syrup (Batch No. 630351 ) by multivariate calibration methods

\begin{tabular}{|c|c|c|c|c|c|c|}
\hline \multirow{3}{*}{$\begin{array}{l}\text { Sample } \\
\text { no. }\end{array}$} & \multirow{2}{*}{\multicolumn{2}{|c|}{$\begin{array}{l}\text { Authentic } \\
\text { added } \\
\mu \mathrm{g} \mathrm{ml}^{-1}\end{array}$}} & \multicolumn{4}{|c|}{ Multivariate calibration methods } \\
\hline & & & \multicolumn{2}{|c|}{ PLS } & \multicolumn{2}{|r|}{ PCR } \\
\hline & CHP & $D X$ & $\begin{array}{c}R \% \text { of } \\
C H P\end{array}$ & $R \%$ of $D X$ & $R \%$ of $C H P$ & $\begin{array}{c}R \% \text { of } \\
D X\end{array}$ \\
\hline 1 & 2 & 1 & 101.96 & 100.90 & 101.67 & 100.01 \\
\hline 2 & 4 & 2 & 98.31 & 99.34 & 97.75 & 98.88 \\
\hline 3 & 6 & 3 & 98.03 & 99.24 & 98.17 & 98.13 \\
\hline \multicolumn{3}{|c|}{ Mean \pm RSD } & $\begin{array}{c}99.43 \pm \\
2.193\end{array}$ & $\begin{array}{c}99.83 \\
\pm 0.932\end{array}$ & $\begin{array}{l}99.20 \pm \\
2.153\end{array}$ & $\begin{array}{c}99.02 \pm \\
0.942\end{array}$ \\
\hline \multicolumn{3}{|c|}{$\begin{array}{l}\text { Found of CHP and DX in } \\
\text { Phenadone syrup* } \% \pm \\
\text { R.S.D.) }\end{array}$} & $\begin{array}{c}98.94 \pm \\
1.692\end{array}$ & $\begin{array}{c}102.33 \pm 1.8 \\
39\end{array}$ & $\begin{array}{c}98.89 \pm 1.73 \\
6\end{array}$ & $102.36 \pm 1.857$ \\
\hline
\end{tabular}

Table 8B: Applying standard addition technique for determination of CHP and DX in phenadone syrup (Batch No. 630351) by HPTLC-densitometric method

\begin{tabular}{|c|c|c|c|c|}
\hline & 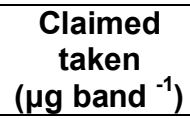 & 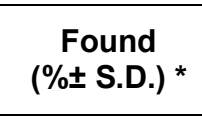 & $\begin{array}{l}\text { Pure added } \\
\left(\mu \text { band }^{-1}\right)\end{array}$ & $\begin{array}{c}\text { Found } \\
\text { (Recovery \%) }\end{array}$ \\
\hline \multirow{3}{*}{$\mathrm{CHP}$} & \multirow{3}{*}{1.6} & \multirow{3}{*}{$\begin{array}{l}100.72 \pm \\
1.053\end{array}$} & 1 & 99.75 \\
\hline & & & 1.6 & 99.54 \\
\hline & & & 2.4 & 97.74 \\
\hline \multicolumn{2}{|c|}{ Mean $\% \pm$ S.D. } & & & $99.01 \pm 1.105$ \\
\hline \multirow{3}{*}{$\mathrm{DX}$} & \multirow{3}{*}{0.4} & \multirow{3}{*}{$\begin{array}{c}102.29 \pm \\
3.979\end{array}$} & 0.4 & 102.31 \\
\hline & & & 0.8 & 98.23 \\
\hline & & & 1.2 & 98.63 \\
\hline Mean & $\pm S D$ & & & $99.72 \pm 2.885$ \\
\hline
\end{tabular}

Table 9: Statistical comparison of the results obtained by the proposed methods and HPLC method [2] in respect of analysis of CHP and DX in pure powder form

\begin{tabular}{lcccccccc}
\hline \multirow{2}{*}{ Item } & \multicolumn{2}{c}{ HPTLC method } & \multicolumn{2}{c}{ PLS method } & \multicolumn{2}{c}{ PCR method } & \multicolumn{2}{c}{$\begin{array}{c}\text { Reported HPLC } \\
\text { method [2] }\end{array}$} \\
\cline { 2 - 8 } & $\mathbf{C H P}$ & $\mathbf{D X}$ & $\mathbf{C H P}$ & $\mathbf{D X}$ & $\mathbf{C H P}$ & $\mathbf{D X}$ & $\mathbf{C H P}$ & DX \\
\cline { 2 - 8 } Mean & 99.73 & 100.11 & 100.06 & 99.88 & 100.06 & 99.88 & 99.93 & 99.96 \\
R.S.D. & 2.096 & 1.914 & 1.196 & 1.639 & 1.198 & 1.647 & 1.920 & 1.746 \\
Variance & 4.393 & 3.663 & 1.430 & 2.686 & 1.435 & 2.713 & 3.686 & 3.049 \\
$\mathrm{~N}$ & 6 & 6 & 18 & 18 & 18 & 18 & 7 & 7 \\
F test & 1.192 & 1.201 & 2.578 & 1.135 & 2.569 & 1.124 & & \\
& $(4.39)$ & $(4.39)$ & $(2.70)$ & $(2.70)$ & $(2.70)$ & $(2.70)$ & & \\
Student's & 0.18 & 0.148 & 0.205 & 0.108 & 0.205 & 0.107 & & \\
t test & $(2.201)$ & $(2.201)$ & $(2.069)$ & $(2.069)$ & $(2.069)$ & $(2.069)$ & & \\
& & & & & & & & \\
\hline
\end{tabular}

lengths. The wavelengths used were in the range $215-290 \mathrm{~nm}$ in all cases. Wavelengths less than $215 \mathrm{~nm}$ were rejected due to the noisy content, while wavelengths $>290 \mathrm{~nm}$ were not used because corresponding components do not absorb in these regions. In this study, two calibration models were proposed, validated and then used for the prediction of unknown samples. Appropriate selection of the number of factors to be used to construct the model is key to achieving correct quantitation in PLS and PCR calibration. The most usual procedure for this purpose involves choosing the number of factors that result in the minimum root mean square error of cross validation (RMSECV). However, this criterion is subjected to some constraints since, occasionally; the RMSECV does not reach a sharp minimum, but decreases gradually above a given number of factors. On the other hand, it is calculated from a finite number of samples, and so it is error-prone. For these reasons, the method developed by Haaland and Thomas [9] was used for selecting the optimum number of factors, which involves selecting that model including the smallest number of factors that results in an insignificant difference between the 
corresponding RMSECV and the minimum RMSECV.

Densitometry offers a simple way of quantifying directly on a TLC plate by measuring the optical density of the separated spots. The amounts of the compounds are determined by comparing them to a standard curve from reference materials chromatographed simultaneously under the same conditions [11]. In the presented work, samples are applied as bands using TLC Linomat IV sample applicator with $100 \mu$ l syring (Camag) where bands have many advantages over spots [12]. Trials were done to choose a developing system, which can affect separation of CHP, DX and Parabens. These systems include ethyl acetate: methanol $(1: 1 \mathrm{v} / \mathrm{v})$ and methanol: chloroform: ammonia $(2: 2: 1 \mathrm{v} / \mathrm{v} / \mathrm{v})$ which did not affect good separation of the three drugs. Complete separation of CHP, DX and Parabens was obtained using chloroform: methanol (93:7 v/v) as a mobile phase. A linear correlation was obtained between peak area of the separated bands and the corresponding concentration in the range of $1-6 \mu \mathrm{g}$ band-1 for $\mathrm{CHP}$ and in the range of $0.4-2 \mu \mathrm{g}$. band-1 for DX.

The regression equations were computed and found to be
$A_{1}(C H P)=1.79223 C_{1}+1.4857(r=0.9997)$
$A_{2}(D X)=3.3431 C_{2}+1.6395(r=0.9996)$

where $A_{1}$ and $A_{2}$ are the integrated area under the peak $\times 10^{-3}$ for CHP and DX respectively. $C_{1}$ and $\mathrm{C}_{2}$ are the concentrations in $\mu \mathrm{g}$ band $^{-1}$ for CHP and DX, respectively, and $r$ is the correlation coefficient.

\section{CONCLUSION}

PCR and PLS methods exhibit simplicity, greater convenience, lower analysis time and more economical than published HPLC methods. With HPTLC-densitometric method, several samples can be run simultaneously using a small quantity of mobile phase, unlike HPLC, thus lowering analysis time and cost per analysis, and it also provides high sensitivity and selectivity. The findings indicate high reproducibility of the proposed methods as well as high sensitivity, accuracy, reproducibility and specificity. Moreover, the methods are simple and inexpensive, thus favouring their application in quality control laboratories.

\section{ACKNOWLEDGEMENT}

The authors would like to extend their sincere appreciation to the Deanship of Scientific Research at King Saud University for funding this research through the Research Group Project no. RGP - VPP - 322.

\section{REFERENCES}

1. Budavari S, O'Neal M, Smith A, Heckelman P, Kinneary $J$. The Merck Index. An Encyclopedia of Chemicals, Drugs, and Biologicals. 12th edn. Whitehouse Station, NJ: Merck \& Co Inc; 1996.

2. Moyano MA, Rosasco MA, Pizzorno MT,Segall Al. Simultaneous determination of chlorpheniramine maleate and dexamethasone in a tablet dosage form by liquid chromatography. J AOAC Int. 2005; 88(6): 1677-1683.

3. Hattori $T$, Washio $Y$, Kamiya $N$, Itoh $Y$, Inoue $M$. High performance liquid chromatographic analysis of drugs. I. Simultaneous determination of dexamethasone and chlorpheniramine maleate in ointment (author's transl)]. Yakugaku zasshi 1979; 99(5):537.

4. El-Yazbi FA, Hammud HH, Assi SA. New spectrofluorometric application for the determination of ternary mixtures of drugs. Anal Chim Acta 2006; 580(1): 39-46.

5. Goicoechea HC, Collado MS, Satuf ML, Olivieri AC. Complementary use of partial least-squares and artificial neural networks for the non-linear spectrophotometric analysis of pharmaceutical samples. Anal Bioanal Chem. 2002; 374(3): 460-465.

6. El-Yazbi F, Korany M, Abdel-Razak O, Elsayed M. Derivative spectrophotometric determination of some corticosteroids in combinations with other drugs. J Assoc Off Anal Chem. 1986; 69(4): 614.

7. Sweetman SC. Martindale-The Complete Drug Reference. 36 ed. London, UK: The Pharmaceutical Press; 2009.

8. Brereton RG. Multilevel multifactor designs for multivariate calibration. Analyst 1997; 122(12): 15211529.

9. Haaland DM, Thomas EV. Partial least-squares methods for spectral analyses. 1. Relation to other quantitative calibration methods and the extraction of qualitative information. Anal Chem. 1988; 60(11): 1193-1202.

10. Beebe K, Pell R, Seasholtz M. Chemometrics. A Practical Guide. New York: John Wiley \& Sons, Inc; 1998.

11. Grinberg N. Modern thin-layer chromatography. New York: Marcel Dekker Incorporation; 1990.

12. Sethi PD. HPTLC: High Performance Thin-layer Chromatography; Quantitative Analysis of Pharmaceutical Formulations. New Delhi, India: CBS Publishers \& Distributors; 1996. 